\title{
Componentes de produção e suas correlações em genótipos de feijão- caupi em cultivo de sequeiro e irrigado ${ }^{1}$
}

\author{
Production components and their correlations in caupi bean genotypes in rainfed and \\ in irrigated cultivation
}

\author{
José Algaci Lopes da Silva ${ }^{2}$ e Josynaria Araújo Neves ${ }^{3 *}$
}

\begin{abstract}
Resumo - Experimentos realizados com feijão-caupi, Vigna unguiculata (L.) Walp., indicam a possibilidade de obtenção de genótipos estáveis com adaptação ampla ao clima e solo, e elevada produtividade, principalmente com o uso de irrigação. Neste experimento, objetivou-se avaliar 20 genótipos de feijão-caupi quanto ao potencial de rendimento e seus componentes. Dezessete linhagens e três cultivares de feijão-caupi, foram avaliadas em cultivo de sequeiro e irrigado, em dois experimentos, no campo experimental do Centro de Pesquisa Agropecuária do Meio-Norte (CPAMN) da Embrapa Meio-Norte, em Teresina-Piauí, no período de abril a dezembro de 2006. O delineamento experimental utilizado foi de blocos completos casualizados, com quatro repetições. Foram avaliados os caracteres: Valor de cultivo (VC), Comprimento da vagem (COMPV), Número de grãos por vagem (NGV), Peso de cem grãos (P100G), Índice de grãos (IG) e Produtividade (PROD). As linhagens MNC99-541F-15, TE96290-12G, MNC99-547F-2, MNC99-510F-16 e TE97-304G-12 e as cultivares BRS-Marataoã e BR-17 Gurguéia apresentaram as maiores produtividades em cultivo de sequeiro. Por outro lado as linhagens MNC99-542F-5, TE96-290-12G, TE97-304G-12, MNC99-541F-18, TE97-309G-24, MNC99510F-16, TE97-304G-4, MNC99-547F-2, MNC99-510F-16 e a cultivar BRS Paraguaçu se destacaram no cultivo irrigado. As linhagens TE96-290-12G, MNC99-510F-16 e TE97-304G-4 apresentaram produtividade adequada em ambos os sistemas de cultivo.
\end{abstract}

Palavras-chave - Vigna unguiculata. Feijão macassar. Melhoramento genético.

\begin{abstract}
Researches with caupi bean, Vigna unguiculata (L.) Walp., indicates the possibility to obtain stable genotypes with broad adaptation to climate and soil, on high productivity, especially with the use of irrigation. The aim of this was to evaluate the yield and its components in 20 genotypes of caupi bean. Seventeen lineages and three cultivars of caupi bean were evaluated in a rainfed cultivation and in an irrigated cultivation, in two experiments. At Teresina-Piauí, in the period of April to December in 2006, on the experimental field of the Middle-north Agricultural Research Center (CPAMN) of Embrapa (Brazilian Company of Agricultural Research) in the Middle-north region. It was used the randomized block design with four replications. The evaluated characters were: initial flowering (FI), length of the main branch (CRP), number of nodes in the main branch (NNRP), number of lateral branches (NRL), layering (ACAM) and productivity (PROD). The MNC99-541F-15, TE96290-12G, MNC99-547F-2, MNC99-510F-16 and TE97-304G-12 lineages and, the BRS-Marataoã and BR-17 Gurguéia cultivars showed the largest productivities in rainfed cultivation. From another standpoint, the MNC99-542F-5, TE96-29012G, TE97-304G-12, MNC99-541F-18, TE97-309G-24, MNC99510F-16, TE97-304G-4, MNC99-547F-2, MNC99-510F-16 lineages and the BRS Paraguaçu cultivar stood out in the irrigated cultivation. The lineages TE96-290-12G, MNC99-510F-16 and TE97-304G-4 showed good productive levels in both cultivation systems.
\end{abstract}

Key words - Vigna unguiculata. Macassar bean. Genetic improvement.

\footnotetext{
* Autor para correspondência

${ }^{1}$ Recebido para publicação em 07/04/2010; aprovado em 04/04/2011

Pesquisa desenvolvida na Universidade Federal do Piauí -UFPI

${ }^{2}$ Universidade Federal do Piauí, Campus Universitário Ministro Petrônio Portella, Bairro Ininga, Teresina-PI, Brasil, 64.049-550, ufpinet@ufpi.br

${ }^{3}$ Universidade Federal do Piauí-UFPI, Teresina-PI, Brasil, josynaria@hotmail.com
} 


\section{Introdução}

O feijão-caupi (Vigna unguiculata (L.) Walp.) é uma leguminosa cultivada nas regiões semiáridas da África, Estados Unidos e Brasil. Neste último, a cultura apresenta grande importância para as regiões Norte e Nordeste, devido à tradição no seu cultivo, comércio e consumo (ROCHA et al., 2009), uma vez que é no Nordeste que se encontram as maiores áreas plantadas (CARDOSO; RIBEIRO, 2006) e o cultivo do feijão-caupi vem a ser uma atividade para o desenvolvimento agrícola, tanto no aspecto econômico como no nutricional, exercendo função socioeconômica, sobretudo para a população rural no suprimento das necessidades nutricionais das populações carentes (TEÓFILO et al., 2008), além de ser fixadora de mão-de-obra no campo (CARDOSO; RIBEIRO, 2006; TÁVORA et al., 2001).

O feijão-caupi vem alcançando quase a totalidade das áreas plantadas com feijão nos Estados do Amazonas, Rio Grande do Norte, Ceará, Piauí e Maranhão (SANTOS et al., 2000). Atualmente existe uma demanda na região Centro-Oeste, onde apresenta avanços tecnológicos, pois é conduzido de forma mecanizada, sendo crescente a demanda por cultivares de porte ereto (ROCHA et al., 2009).

Estudos de adaptabilidade e estabilidade têm mostrado que é possível se obter genótipos estáveis com adaptação ampla e elevada produtividade (FREIRE FILHO et al., 2001; 2002; SANTOS et al., 2000).

O feijão-caupi é amplamente cultivado por pequenos agricultores em cultivo de sequeiro, em sistema de consórcio associadas a outras culturas comuns da região, pois se adapta bem às condições de solo, clima e sistemas e, ultimamente vem tendo uma expansão de sua área em cultivos comerciais sob condição de irrigação para ser alcançadas elevadas produtividades de grãos (CARDOSO et al., 1996).

No Piauí, a produtividade média da cultura do feijãocaupi varia entre 217,10 a $740,74 \mathrm{~kg} \mathrm{ha}^{-1}$, conforme a safra e o tipo de cultivo (IBGE, 2006). No entanto, os níveis de produtividade alcançados em regime irrigado, $1.200 \mathrm{~kg} \mathrm{ha}^{-1}$, pode alcançar rendimentos médios superiores a $2.500 \mathrm{~kg} \mathrm{ha}^{-1}$ conforme resultados obtidos em distantes regiões de acordo com Freire Filho et al. (2007), que evidenciam um manejo adequado, com adoção de um nível de tecnologia compatível com a utilização da irrigação, correção do solo e adubação, notadamente durante as fases vegetativa e reprodutiva, quando se busca maximizar a eficiência do uso de água pela cultura (ANDRADE JÚNIOR et al., 2002), prática com alta correlação com a produtividade.

O conhecimento da associação entre caracteres agronômicos e morfológicos pode ser primordial quando da necessidade de ser feita seleção simultânea de caracteres. Além disso, ao selecionar caracteres de alta herdabilidade e de fácil aferição, que evidenciem alta correlação com o caráter desejado, o melhorista poderá obter progressos mais rápidos em relação ao uso da seleção direta (CARVALHO et al., 2004).

Desta forma, este experimento teve como objetivo avaliar 20 genótipos de feijão-caupi de porte semiprostrado, quanto ao potencial de rendimento e seus componentes, em cultivo de sequeiro e irrigado, nas condições edafoclimatológicas de Teresina-PI.

\section{Material e métodos}

O material genético constitui-se de três cultivares e dezessete linhagens de feijão-caupi (TAB. 1) originárias do banco de germoplasma do Programa de Melhoramento Genético de Feijão-Caupi da Embrapa Meio-Norte. Os tratamentos foram constituídos dos 20 genótipos, sendo as três cultivares consideradas testemunhas.

O cultivo de sequeiro foi instalado em um Latossolo Vermelho Amarelo, textura areia franca (EMBRAPA, 1999), no período de abril a junho de 2006. O cultivo irrigado por aspersão convencional foi conduzido em um Neossolo Flúvico moderado, textura Franco ArgiloArenoso (EMBRAPA, 1999), no período de setembro a novembro de 2006, ambos no município de Teresina - Piauí, em área experimental da Embrapa Meio-Norte, localizada a $05^{\circ} 05^{\prime}$ de latitude Sul, $42^{\circ} 48^{\prime}$ de longitude Oeste e 72 $\mathrm{m}$ de altitude. A região apresenta clima classificado como tropical sub-úmido quente.

O delineamento experimental adotado foi o de blocos completos casualizados, com 20 tratamentos e quatro repetições. As parcelas tiveram as dimensões de 3,0 m x 5,0 m, com quatro fileiras de 5,0 m de comprimento e área útil $1,5 \mathrm{~m} \times 5 \mathrm{~m}\left(7,50 \mathrm{~m}^{2}\right)$ formada pelas duas fileiras centrais. $\mathrm{O}$ espaçamento entre fileiras foi de $0,75 \mathrm{~m}$ e dentro da fileira foi de $0,25 \mathrm{~m}$ entre covas. $\mathrm{Na}$ semeadura foram colocadas quatro sementes por cova. O desbaste foi realizado 20 dias após plantio, com compensação das falhas, deixando-se em média duas plantas por cova, o que resultou em uma população equivalente a 106,6 mil plantas por hectare.

Foram avaliados os caracteres relacionados à produção de grãos: Valor de Cultivo (VC) - valor determinado a partir da leitura realizada no início da maturidade das vagens, considerando o aspecto geral da planta, vigor, arquitetura, carrego e as características da vagem, dos grãos e o aspecto fitossanitário (TAB. 2); Comprimento de Vagem (COMPV) - comprimento, em $\mathrm{cm}$, de cinco vagens tiradas ao acaso de cada parcela; 
Tabela 1 - Relação das linhagens e cultivares de feijão-caupi utilizados nos experimentos em cultivos de sequeiro e irrigado por aspersão

\begin{tabular}{|c|c|c|c|c|}
\hline $\begin{array}{l}\text { Código da } \\
\text { Linhagem }\end{array}$ & Parentais & $\begin{array}{c}\text { Classe } \\
\text { comercial }\end{array}$ & $\begin{array}{l}\text { Subclasse } \\
\text { comercial }\end{array}$ & Cor do grão \\
\hline MNC99-505G-11 & Canapuzinho x BR17-Gurguéia & Cores & Mulato & Marrom claro \\
\hline MNC99-507G-1 & BR14-Mulato x Canapuzinho & Cores & Mulato & Marrom claro \\
\hline MNC99-507G-8 & BR14-Mulato x Canapuzinho & Cores & Mulato & Marrom claro \\
\hline MNC99-508G-1 & TE90-180-88F x Canapuzinho & Cores & Mulato & Marrom claro \\
\hline MNC99-510G-8 & Paulista $x$ TE90-180-88F & Cores & Sempre-verde & Esverdeado \\
\hline MNC99-510F-16 & Paulista $\mathrm{x}$ TE90-180-88F & Cores & Mulato & Marrom claro \\
\hline TE97-309G-18 & CNCx 405-24f x CNCx 689-128G & Cores & Mulato & Marrom claro \\
\hline TE97-304G-4 & CNCx 405-17F x TE94-268-3D & Cores & Mulato & Marrom claro \\
\hline TE97-304G-12 & CNCX 405-17F x TE94-268-3D & Cores & Mulato & Marrom claro \\
\hline TE97-309G-24 & CNCX $405-24 \mathrm{~F}$ x CNCx 689-128G & Cores & Mulato & Marrom claro \\
\hline TE96-290-12G & TE97-108-6G x TE97-98-8G & Cores & Branco & Branco \\
\hline MNC99-541F-15 & TE93-210-13F x TE96-282-22G & Cores & Branco & Branco \\
\hline MNC99-541F-18 & TE93-219-13F x TE96-282-22G & Cores & Branco & Branco \\
\hline MNC99-541F-21 & TE93-210-13F $\times$ TE96-282-22G & Cores & Branco & Branco \\
\hline MNC99-542F-5 & TE96-282-22G x TE93-210-13F & Cores & Branco & Branco \\
\hline MNC99-542F-7 & TE96-282-22G x TE93-210-13F & Cores & Branco & Branco \\
\hline MNC99-547F-2 & (TE97-406-1F x IT87D-611-3) x TE97-404-1F & Cores & Sempre-verde & Esverdeado \\
\hline BRS Paraguaçu & BR10-Piauí x Aparecido Moita & Cores & Branco & Branco \\
\hline BR 17-Gurguéia & BR 10-Piauí x CE-315 & Cores & Sempre-verde & Esverdeado \\
\hline BRS Maratoã & Seridó x TVx 1836-013J & Cores & Sempre-verde & Esverdeado \\
\hline
\end{tabular}

Tabela 2 - Escala para leitura do valor de cultivo ${ }^{1}$

\begin{tabular}{cc}
\hline Escala & Característica \\
\hline 1 & Planta sem características adequadas ao cultivo comercial \\
3 & Planta com poucas características apropriadas ao cultivo comercial \\
4 & Planta com boa parte das características adequadas ao cultivo comercial \\
5 & Planta com a maioria das características adequadas para o cultivo comercial \\
6 & Planta com todas as características adequadas ao cultivo comercial \\
7 & Planta com excelentes características para o cultivo comercial \\
\hline
\end{tabular}

Fonte: Embrapa Meio-Norte (planilha de acompanhamento de ensaios, 2006); ${ }^{1} \mathrm{O}$ valor determinado a partir da leitura realizada no início da maturidade das vagens, considerando o aspecto geral da planta, vigor, arquitetura, carrego e as características da vagem, dos grãos e o aspecto fitossanitários

Número de Grãos por Vagem (NGV) - contagem obtida da média de cinco vagens tiradas ao acaso; Peso de 100 grãos (P100G) - valor médio obtido da contagem em g, os grãos foram uniformizados quanto a umidade que variou entre $10 \%$ e $12 \%$, em seguida, as amostras foram separadas por um tabuleiro contador, em duas repetições de 100 sementes e pesadas em balança de precisão em cada parcela; Índice de grãos (IG) - valor obtido a partir da porcentagem do peso dos grãos em relação ao peso total da vagem, obtido pela seguinte fórmula: IG $(\%)=(\mathrm{PG} 5 \mathrm{~V} / \mathrm{P} 5 \mathrm{~V}) .100$ onde, $\mathrm{PG} 5 \mathrm{~V}=$ peso dos grãos de 5 vagens e $\mathrm{P} 5 \mathrm{~V}=$ peso das 5 vagens e; Produtividade (PROD) - determinada pela produção total de grãos na área útil da parcela, transformada de $\mathrm{g}$ parcela ${ }^{-1}$ para $\mathrm{kg} \mathrm{ha}^{-1}$. 
Os dados foram submetidos à análise de variância. Para a comparação das médias empregou-se o teste Scott \& Knott (1974) aos níveis de significância de 5\% e 1\%. Utilizou-se o software SAEG, versão 9.1, da Universidade Federal de Viçosa - UFV, Minas Gerais.

Nos parâmetros valor de cultivo, comprimento de vagem, número de grãos por vagem, peso de 100 grãos e índice de grãos as análises foram realizadas com base na média de dados coletados em cinco plantas tomadas ao acaso na parcela.

Para a estimativa das correlações foram utilizados os dados originais dos caracteres coletados em toda a parcela e a média das observações para os caracteres obtidos por meio de amostras dentro da parcela. As análises de variâncias, covariâncias e a estimativa dos coeficientes de correlação foram estimadas segundo Kempthorne (1973).

A partir da análise de variância foram determinados os coeficientes de variação experimental e genética e realizado o cálculo das correlações fenotípicas, genotípicas e ambientais entre os caracteres estudados. A significância dos coeficientes de correlação foi avaliada pelo teste t (CRUZ, 1994).

\section{Resultados e discussão}

Os resultados das análises de variâncias dos caracteres relacionados à produção de grãos em cultivo de sequeiro encontram-se na Tabela 3.

$\mathrm{O}$ efeito de genótipos mostrou-se altamente significativo para todos os caracteres. Isso indica que os genótipos apresentaram grande variabilidade de forma semelhante aos verificados por Rocha et al. (2003) e Freire Filho et al. (2001, 2002, 2003), que também detectaram efeito de genótipo significativo para produtividade de grãos. Os valores do coeficiente de variação foram relativamente baixos, exceção feita aos do valor de cultivo e da produtividade, sem afetar a precisão do experimento.
As médias dos caracteres relacionados com a produtividade de grãos em cultivo de sequeiro encontramse na Tabela 4. Verificou-se diferenças entre os genótipos para todos os caracteres, confirmando a existência de variabilidade genética para todos eles. Para o valor de cultivo a média geral foi de 3,7. Verificou-se uma separação de genótipos em dois grupos, um grupo que apresentou os maiores valores, com destaque para a cultivar BRS-Marataoã, com valor de cultivo igual a 5,0, e para a linhagem MNC99-541F-18, com valor de cultivo 4,75. Embora não tenha diferido de outros cinco genótipos, seus valores de cultivo indicam que estes exemplares apresentam a maioria de suas características adequadas ao cultivo comercial.

Considerando o vigor, a arquitetura, as características de vagem e dos grãos, além do aspecto fitossanitário, é sabido que a escolha correta da cultivar para um determinado ambiente e sistema de produção é de grande importância para a obtenção de uma boa produtividade. Contudo, é necessário, também, que a cultivar tenha características de grão e de vagem, que atendam às exigências de comerciantes e consumidores (FREIRE FILHO et al., 2000).

O caráter comprimento de vagem apresentou média geral de 19,68 cm, sendo os genótipos também foram separados em dois grupos, onde um grupo obteve média de comprimento de vagem acima de 20 $\mathrm{cm}$, englobando metade dos genótipos, e outro com vagens de comprimento inferior a $20 \mathrm{~cm}$. Percebe-se que neste grupo não apresenta valores situados dentro dos padrões comerciais, acima de $20 \mathrm{~cm}$.

No trabalho de Oliveira et al. (2002), com exceção das linhagens TE-90-180-9F; TE-90-180-88F e da cultivar BR-02 Bragança, os valores obtidos para o comprimento e peso médio de vagens situaram-se dentro dos padrões comerciais acima de $20 \mathrm{~cm}$ para o comprimento e acima de $14 \mathrm{~g}$ para o peso de vagens, corroborando com resultados obtidos neste trabalho.

Tabela 3 - Análises de variâncias dos caracteres relacionados com a produção de grãos no experimento em cultivo de sequeiro, Teresina - PI, 2006

\begin{tabular}{cccccccc}
\hline \multirow{2}{*}{$\begin{array}{c}\text { Fontes de } \\
\text { variação }\end{array}$} & GL & $\begin{array}{c}\text { Valor de } \\
\text { cultivo }\end{array}$ & $\begin{array}{c}\text { Comprimento } \\
\text { de vagem }\end{array}$ & $\begin{array}{c}\text { Número de grãos } \\
\text { por vagem }\end{array}$ & $\begin{array}{c}\text { Peso de } 100 \\
\text { grãos }\end{array}$ & $\begin{array}{c}\text { Índice de } \\
\text { grãos }\end{array}$ & Produtividade \\
\hline Genótipos & 19 & $1,78^{* *}$ & $5,45^{* *}$ & $6,02^{* *}$ & $34,12^{* *}$ & $0,42^{* *}$ & $64258,49^{* *}$ \\
Blocos & 3 & 6,00 & 1,74 & 1,63 & 6,80 & 0,26 & 33559,72 \\
Resíduo & 57 & 0,44 & 0,95 & 2,00 & 2,63 & 0,14 & 22153,05 \\
\hline C.V. $(\%)$ & & 19,90 & 4,96 & 9,88 & 8,66 & 5,02 & 17,47 \\
\hline
\end{tabular}

$\left({ }^{* *}\right)$ Significativo ao nível de $1 \%$ pelo teste $\mathrm{F}$ 
Tabela 4 - Médias dos caracteres relacionados com a produtividade de grãos de 20 genótipos de feijão-caupi cultivados em regime de sequeiro, Teresina - PI, 2006

\begin{tabular}{|c|c|c|c|c|c|c|}
\hline Genótipo $^{(1)}$ & $\begin{array}{l}\text { Valor de } \\
\text { cultivo }\end{array}$ & $\begin{array}{l}\text { Comprimento } \\
\text { de vagem }(\mathrm{cm})\end{array}$ & $\begin{array}{c}\text { Número de grãos } \\
\text { por vagem }\end{array}$ & $\begin{array}{l}\text { Peso de } 100 \\
\text { grãos }(\mathrm{g})\end{array}$ & $\begin{array}{l}\text { Índice de } \\
\text { grãos (\%) }\end{array}$ & $\begin{array}{c}\text { Produtividade } \\
\left(\mathrm{kg} \mathrm{ha}^{-1}\right)\end{array}$ \\
\hline MNC99-505G-11 & $3,50 \mathrm{~B}$ & $20,60 \mathrm{~A}$ & $15,80 \mathrm{~A}$ & $20,60 \mathrm{~B}$ & $0,73 \mathrm{~B}$ & $668,7 \mathrm{~B}$ \\
\hline MNC99-507G-4 & $3,00 \mathrm{~B}$ & $20,50 \mathrm{~A}$ & $15,00 \mathrm{~A}$ & $19,00 \mathrm{~B}$ & $0,75 \mathrm{~A}$ & $722,1 \mathrm{~B}$ \\
\hline MNC99-507G-8 & $3,25 \mathrm{~B}$ & $19,10 \mathrm{~B}$ & $14,10 \mathrm{~A}$ & $17,60 \mathrm{C}$ & $0,72 \mathrm{~B}$ & 790,4 B \\
\hline MNC99-508G-1 & $3,75 \mathrm{~B}$ & $20,60 \mathrm{~A}$ & $14,40 \mathrm{~A}$ & $16,90 \mathrm{C}$ & $0,71 \mathrm{~B}$ & $786,5 \mathrm{~B}$ \\
\hline MNC99-519G-8 & $3,00 \mathrm{~B}$ & $20,30 \mathrm{~A}$ & $14,60 \mathrm{~A}$ & $17,70 \mathrm{C}$ & $0,72 \mathrm{~B}$ & $792,1 \mathrm{~B}$ \\
\hline MNC99-510F-16 & $3,75 \mathrm{~B}$ & $21,20 \mathrm{~A}$ & $15,30 \mathrm{~A}$ & $17,70 \mathrm{C}$ & $0,75 \mathrm{~A}$ & $1.001,1 \mathrm{~A}$ \\
\hline TE97-309G-18 & $3,75 \mathrm{~B}$ & $20,00 \mathrm{~A}$ & $13,40 \mathrm{~B}$ & $20,60 \mathrm{~B}$ & $0,70 \mathrm{~B}$ & $658,2 \mathrm{~B}$ \\
\hline TE97-304G-4 & $3,75 \mathrm{~B}$ & $21,00 \mathrm{~A}$ & $15,80 \mathrm{~A}$ & $19,50 \mathrm{~B}$ & $0,75 \mathrm{~A}$ & $878,0 \mathrm{~B}$ \\
\hline TE97-304G-12 & $2,75 \mathrm{~B}$ & $20,40 \mathrm{~A}$ & $14,90 \mathrm{~A}$ & $17,40 \mathrm{C}$ & $0,66 \mathrm{~B}$ & $909,6 \mathrm{~A}$ \\
\hline TE97-309G-24 & $4,50 \mathrm{~A}$ & $18,60 \mathrm{~B}$ & $13,90 \mathrm{~B}$ & $17,30 \mathrm{C}$ & $0,70 \mathrm{~B}$ & $848,0 \mathrm{~B}$ \\
\hline TE96-290-12G & $3,25 \mathrm{~B}$ & $19,10 \mathrm{~B}$ & $14,60 \mathrm{~A}$ & $15,30 \mathrm{D}$ & $0,78 \mathrm{~A}$ & $1.020,5 \mathrm{~A}$ \\
\hline MNC99-541F-15 & $4,25 \mathrm{~A}$ & $20,00 \mathrm{~A}$ & $13,60 \mathrm{~B}$ & $20,10 \mathrm{~B}$ & $0,78 \mathrm{~A}$ & $1.070,3 \mathrm{~A}$ \\
\hline MNC99-541F-18 & $4,75 \mathrm{~A}$ & $21,80 \mathrm{~A}$ & $12,70 \mathrm{~B}$ & $25,80 \mathrm{~A}$ & $0,76 \mathrm{~A}$ & 864,8 B \\
\hline MNC99-541F-21 & $4,25 \mathrm{~A}$ & $18,40 \mathrm{~B}$ & $13,10 \mathrm{~B}$ & $21,30 \mathrm{~B}$ & $0,77 \mathrm{~A}$ & $739,5 \mathrm{~B}$ \\
\hline MNC99-542F-5 & $3,50 \mathrm{~B}$ & $18,30 \mathrm{~B}$ & $11,50 \mathrm{~B}$ & $20,90 \mathrm{~B}$ & $0,75 \mathrm{~A}$ & 747,2 B \\
\hline MNC99-542F-7 & $4,25 \mathrm{~A}$ & $17,60 \mathrm{~B}$ & $12,10 \mathrm{~B}$ & $22,50 \mathrm{~B}$ & $0,79 \mathrm{~A}$ & $723,8 \mathrm{~B}$ \\
\hline MNC99-547F-2 & $3,25 \mathrm{~B}$ & $19,60 \mathrm{~B}$ & $14,40 \mathrm{~A}$ & $18,70 \mathrm{C}$ & $0,76 \mathrm{~A}$ & $1.002,7 \mathrm{~A}$ \\
\hline BRS Paraguaçu & $2,50 \mathrm{~B}$ & $19,30 \mathrm{~B}$ & $14,90 \mathrm{~A}$ & $16,70 \mathrm{C}$ & $0,76 \mathrm{~A}$ & 831,3 B \\
\hline BR17-Gurguéia & $4,00 \mathrm{~A}$ & $17,80 \mathrm{~B}$ & $15,50 \mathrm{~A}$ & $12,70 \mathrm{E}$ & $0,73 \mathrm{~B}$ & $950,8 \mathrm{~A}$ \\
\hline BRS- Maratoã & $5,00 \mathrm{~A}$ & $18,90 \mathrm{~B}$ & $15,20 \mathrm{~A}$ & $15,00 \mathrm{D}$ & $0,71 \mathrm{~B}$ & $1.025,4 \mathrm{~A}$ \\
\hline Média Geral & 3,70 & 19,68 & 14,26 & 18,71 & 0,75 & 851,59 \\
\hline C.V. (\%) & 19,90 & 4,96 & 9,88 & 8,66 & 5,02 & 17,47 \\
\hline
\end{tabular}

${ }^{(1)}$ Genótipos com médias não seguidas pela mesma letra diferem pelo teste de Scott \& Knott a 5\% de significância

No caráter número de grãos por vagem, a média foi de 14,26 grãos por vagens e foram formados dois grupos. No primeiro grupo sobressaíram-se as linhagens MNC99-505C-11 e TE97-304G-4, com uma média de 15,80 grãos por vagem, igualando-se estatisticamente a outros 13 genótipos. Tanto o comprimento de vagem como o número de grãos por vagem ficaram dentro das médias obtidas por Freire Filho et al. (2000) para a região meio-norte de 18,0 cm e 14,0 grãos, respectivamente. Uma vez que essas características são desejáveis para a colheita manual, pois, quanto maior a vagem maior é o número de grãos por vagem.

A cultura do feijão-caupi tem tido avanços científicos e técnicos importantes. Entre eles merece destaque a arquitetura de planta. Os caracteres que formam a arquitetura da planta em feijão-caupi, tais como: hábito de crescimento e comprimento do hipocótilo, dos entrenós, dos ramos principais e secundários e do pedúnculo, podem resultar em maior ou menor acamamento das plantas, bem como permitir a colheita mecânica ou facilitar a colheita manual (ROCHA et al., 2009). Além disso, os comerciantes preferem genótipos que sejam fáceis de debulhar e que apresentem boa conservação pós-colheita (ROCHA et al., 2006).

Obteve-se uma amplitude de 12,7 a 25,8 g para o caráter peso de 100 grãos, o mesmo apresentou média de $18,7 \mathrm{~g}$. Neste parâmetro foram formados cinco grupos de genótipos, com destaque para dois deles. Um grupo que teve apenas a linhagem MNC99-541F-18, com o peso de 25,8 g por 100 grãos e outro com seis genótipos, com peso superior a $20 \mathrm{~g}$.

O tamanho do grão, assim como a cor, constitui uma preferência de mercado e são importantes na formação do preço do produto, sendo caracteres que não devem ser marcantemente alterados durante o processo de 
seleção. Visto que existe uma preferência por grãos com peso de 100 grãos em torno de $18 \mathrm{~g}$ de formatos reniforme ou arredondado. Dessas características, entretanto, a cor parece ser o fator mais importante na formação do preço do produto. Considera-se importante que o produtor procure usar cultivares que tenham grãos bem aceitos pelos comerciantes e consumidores (FREIRE FILHO et al., 2000, 2001, 2002, 2003).

$\mathrm{O}$ índice de grãos apresentou média geral de 0,752 ou $75,2 \%$. Mereceram destaque as linhagens MNC99-542F-7, MNC99-541F-15 e TE96-290-12G que apresentaram índices superiores a 78\%.

A produtividade de grãos variou de 658,2 a $1.070,3 \mathrm{~kg} \mathrm{ha}^{-1}$, apresentando grupos de genótipos com produtividades acima de $1.000 \mathrm{~kg} \mathrm{ha}^{-1}$, com destaque para o grupo das linhagens MN99-541F-15 (1.070,3 $\left.\mathrm{kg} \mathrm{ha}^{-1}\right)$, TE96290-12G (1.020,5 $\left.\mathrm{kg} \mathrm{ha}^{-1}\right)$, MNC99-547F-2 (1.002,7 $\left.\mathrm{kg} \mathrm{ha}^{-1}\right) \mathrm{e}$ MNC99-510F-16 (1.000,1 kg ha $\left.{ }^{-1}\right)$ e a cultivar BRS-Marataoã (1.025,4 kg ha-1).

Segundo dados do IBGE (2006) a produtividade média da cultura do feijão-caupi no Piauí pode atingir $740,74 \mathrm{~kg} \mathrm{ha}^{-1}$. Levando em conta que o cultivo é sob sequeiro esses resultados foram bastante promissores, uma vez que a média geral do ensaio foi maior que a obtida por Freire et al. (2001 e 2002), respectivamente, $794 \mathrm{e} 846 \mathrm{~kg} \mathrm{ha}^{-1}$, embora se igualando à média obtida por Freire et al. (2003), de $1.062 \mathrm{~kg} \mathrm{ha}^{-1}$ com os genótipos BR 17-Gurguéia, EPACE-10, Canapuzinho, TE93-21312F-1, TE93-244-23F e TE94-269-1E.

Os resultados das análises de variâncias dos caracteres relacionados à produção de grãos em cultivo irrigado encontram-se na Tabela 5. O efeito de genótipo foi significativo para todos os caracteres. Os valores dos coeficientes de variação variaram de baixo a médio, indicando boa precisão experimental.

As médias dos caracteres relacionados à produtividade de grãos do experimento conduzido em cultivo irrigado por aspersão são apresentadas na Tabela 6.

A cultivar BR17-Gurguéia foi a que apresentou o maior escore para o valor de cultivo, 4,0. Outros 10 genótipos, dentre eles a cultivar BRS-Marataoã e a linhagem TE97-309G-24, apresentaram escore 3. Os demais genótipos tiveram escores abaixo da média, sendo estes genótipos considerados com poucas ou sem características adequadas ao cultivo comercial. Não atendo as principais exigências dos comerciantes e consumidores que são as características de grão e de vagem (FREIRE FILHO et al., 2000).

Os genótipos apresentaram média geral para o comprimento de vagem de $19,98 \mathrm{~cm}$. Neste caráter foramse dois grupos, cada um com de dez genótipos, o primeiro englobando genótipos que tiveram comprimento de vagens acima de $20 \mathrm{~cm}$, merecendo destaque as linhagens TE97304G-4 e MNC99-541F-18, com comprimento de vagem 21,7 e $21,2 \mathrm{~cm}$, respectivamente.

A média geral para o caráter número de grãos por vagem foi de 15,91, onde se verificou a separação de genótipos em dois grupos, um grupo que apresentou os maiores valores, com destaque para a linhagem TE97304G-12 e para a cultivar BRS-Marataoã, com uma média de 17 e 17,4 grãos por vagem, respectivamente. Embora esses não tenha diferido de outros 10 genótipos. E outro grupo com oito genótipos, com o número de grãos por vagem inferior a 15,5 .

Segundo Cardoso et al. (2005), a produtividade dos grãos do feijão-caupi resulta do número de vagens por unidade de área, do número de grãos por vagens e do peso de 1.000 grãos. Sabe-se que vagens grandes e com muitos grãos favorecem a colheita manual. Todavia, para as colheitas semi-mecanizadas e mecanizadas essas duas características não são favoráveis. Nesses dois últimos tipos de colheitas, vagens menores, com menor número de grãos e, conseqüentemente mais leves, que reduzam a possibilidade de dobramento e quebra

Tabela 5 - Resultados das análises de variâncias dos caracteres relacionados com a produção de grãos no experimento em cultivo irrigado por aspersão, Teresina, PI, 2006

\begin{tabular}{cccccccc}
\hline \multirow{2}{*}{$\begin{array}{l}\text { Fonte de } \\
\text { variação }\end{array}$} & GL & $\begin{array}{c}\text { Valor de } \\
\text { cultivo }\end{array}$ & $\begin{array}{c}\text { Comprimento } \\
\text { de vagem }\end{array}$ & $\begin{array}{c}\text { Número de grãos } \\
\text { por vagem }\end{array}$ & $\begin{array}{c}\text { Peso de } 100 \\
\text { grãos }\end{array}$ & $\begin{array}{c}\text { Índice de } \\
\text { grãos }\end{array}$ & Produtividade \\
\hline Genótipos & 19 & $2,24^{* *}$ & $3,58^{* *}$ & $3,38^{*}$ & $16,00^{* *}$ & $0,49^{* *}$ & $219156,9^{* *}$ \\
Blocos & 3 & 0,20 & 1,32 & 2,48 & 7,68 & 0,27 & 124448,9 \\
Resíduo & 57 & 0,12 & 1,08 & 1,61 & 0,90 & 0,11 & 60478,6 \\
\hline C.V. $(\%)$ & & 13,92 & 5,20 & 7,98 & 5,37 & 4,25 & 17,12 \\
\hline
\end{tabular}

$(*, * *)$ Significativo ao nível de $5 \%$ e $1 \%$, respectivamente, pelo teste $\mathrm{F}$ 
Tabela 6 - Médias dos caracteres relacionados com a produção de grãos de 20 genótipos de feijão-caupi cultivados sob irrigação por aspersão, Teresina, PI, 2006

\begin{tabular}{ccccccc}
\hline \multirow{2}{*}{ Genótipo $^{(1)}$} & $\begin{array}{c}\text { Valor de } \\
\text { cultivo }\end{array}$ & $\begin{array}{c}\text { Comprimento } \\
\text { de vagem }(\mathrm{cm})\end{array}$ & $\begin{array}{c}\text { Número de grãos } \\
\text { por vagem }\end{array}$ & $\begin{array}{c}\text { Peso de 100 } \\
\text { grãos (g) }\end{array}$ & $\begin{array}{c}\text { Índice de } \\
\text { grãos (\%) }\end{array}$ & $\begin{array}{c}\text { Produtividade } \\
\left.\text { kg ha }^{-1}\right)\end{array}$ \\
\hline MNC99-505G-11 & $2,00 \mathrm{C}$ & $20,2 \mathrm{~A}$ & $15,3 \mathrm{~B}$ & $19,2 \mathrm{~B}$ & $0,797 \mathrm{~A}$ & $1.412,8 \mathrm{~B}$ \\
MNC99-507G-4 & $3,00 \mathrm{~B}$ & $20,1 \mathrm{~A}$ & $16,0 \mathrm{~A}$ & $21,1 \mathrm{~A}$ & $0,819 \mathrm{~A}$ & $1.349,4 \mathrm{~B}$ \\
MNC99-507G-8 & $3,00 \mathrm{~B}$ & $18,8 \mathrm{~B}$ & $16,0 \mathrm{~A}$ & $17,7 \mathrm{C}$ & $0,777 \mathrm{~B}$ & $982,0 \mathrm{~B}$ \\
MNC99-508G-1 & $2,00 \mathrm{C}$ & $20,6 \mathrm{~A}$ & $16,9 \mathrm{~A}$ & $16,6 \mathrm{C}$ & $0,737 \mathrm{~B}$ & $1.438,8 \mathrm{~B}$ \\
MNC99-519G-8 & $1,25 \mathrm{D}$ & $20,9 \mathrm{~A}$ & $16,5 \mathrm{~A}$ & $17,7 \mathrm{C}$ & $0,771 \mathrm{~B}$ & $1.057,3 \mathrm{~B}$ \\
MNC99-510F-16 & $1,75 \mathrm{C}$ & $20,7 \mathrm{~A}$ & $16,5 \mathrm{~A}$ & $15,0 \mathrm{D}$ & $0,739 \mathrm{~B}$ & $1.518,1 \mathrm{~A}$ \\
TE97-309G-18 & $3,00 \mathrm{~B}$ & $19,4 \mathrm{~B}$ & $15,4 \mathrm{~B}$ & $16,7 \mathrm{C}$ & $0,732 \mathrm{~B}$ & $1.589,4 \mathrm{~A}$ \\
TE97-304G-4 & $3,00 \mathrm{~B}$ & $21,7 \mathrm{~A}$ & $15,8 \mathrm{~A}$ & $19,2 \mathrm{~B}$ & $0,820 \mathrm{~A}$ & $1.495,2 \mathrm{~A}$ \\
TE97-304G-12 & $2,00 \mathrm{C}$ & $20,6 \mathrm{~A}$ & $17,0 \mathrm{~A}$ & $18,4 \mathrm{~B}$ & $0,819 \mathrm{~A}$ & $1.670,7 \mathrm{~A}$ \\
TE97-309G-24 & $3,00 \mathrm{~B}$ & $19,4 \mathrm{~B}$ & $16,3 \mathrm{~A}$ & $17,2 \mathrm{C}$ & $0,797 \mathrm{~A}$ & $1.590,1 \mathrm{~A}$ \\
TE96-290-12G & $2,00 \mathrm{C}$ & $20,8 \mathrm{~A}$ & $16,3 \mathrm{~A}$ & $16,7 \mathrm{C}$ & $0,803 \mathrm{~A}$ & $1.694,5 \mathrm{~A}$ \\
MNC99-541F-15 & $2,00 \mathrm{C}$ & $20,6 \mathrm{~A}$ & $14,9 \mathrm{~B}$ & $18,8 \mathrm{~B}$ & $0,777 \mathrm{~B}$ & $1.361,0 \mathrm{~B}$ \\
MNC99-541F-18 & $3,00 \mathrm{~B}$ & $21,2 \mathrm{~A}$ & $14,6 \mathrm{~B}$ & $19,0 \mathrm{~B}$ & $0,827 \mathrm{~A}$ & $1.656,0 \mathrm{~A}$ \\
MNC99-541F-21 & $3,00 \mathrm{~B}$ & $19,3 \mathrm{~B}$ & $15,5 \mathrm{~B}$ & $17,6 \mathrm{C}$ & $0,832 \mathrm{~A}$ & $1.323,6 \mathrm{~B}$ \\
MNC99-542F-5 & $3,00 \mathrm{~B}$ & $19,4 \mathrm{~B}$ & $13,8 \mathrm{~B}$ & $20,5 \mathrm{~A}$ & $0,822 \mathrm{~A}$ & $1.831,9 \mathrm{~A}$ \\
MNC99-542F-7 & $3,00 \mathrm{~B}$ & $19,1 \mathrm{~B}$ & $15,0 \mathrm{~B}$ & $19,5 \mathrm{~B}$ & $0,836 \mathrm{~A}$ & $1.289,4 \mathrm{~B}$ \\
MNC99-547F-2 & $2,00 \mathrm{C}$ & $19,8 \mathrm{~B}$ & $15,3 \mathrm{~B}$ & $17,4 \mathrm{C}$ & $0,792 \mathrm{~A}$ & $1.092,9 \mathrm{~B}$ \\
BRS Paraguaçu & $1,00 \mathrm{D}$ & $19,8 \mathrm{~B}$ & $16,4 \mathrm{~A}$ & $17,1 \mathrm{C}$ & $0,852 \mathrm{~A}$ & $1.763,2 \mathrm{~A}$ \\
BR17-Gurguéia & $4,00 \mathrm{~A}$ & $17,9 \mathrm{~B}$ & $16,9 \mathrm{~A}$ & $12,2 \mathrm{E}$ & $0,787 \mathrm{~B}$ & $1.298,8 \mathrm{~B}$ \\
BRS- Marataoã & $3,00 \mathrm{~B}$ & $18,9 \mathrm{~B}$ & $17,4 \mathrm{~A}$ & $15,6 \mathrm{D}$ & $0,757 \mathrm{~B}$ & $1.311,3 \mathrm{~B}$ \\
\hline Média Geral & 2,5 & 19,98 & 15,91 & 17,7 & 0,795 & $1.436,36$ \\
\hline CV(\%) & 13,92 & 5,2 & 7,98 & 5,37 & 4,25 & 17,12 \\
\hline G & & & &
\end{tabular}

${ }^{(1)}$ Genótipos com médias não seguidas pela mesma letra diferem pelo teste de Scott \& Knott a 5\% de significância

do pedúnculo são desejáveis. Essas características reduzem a possibilidade da vagem encostar-se ao solo e, consequentemente, a ocorrência de perdas por apodrecimento de vagens e de grãos.

No peso de 100 grãos a média geral foi de $17,70 \mathrm{~g}$, com destaque das linhagens MNC99-507G-4 e MNC99$542 \mathrm{~F}-5$, com médias de 21,1 e $20,5 \mathrm{~g}$, respectivamente. Seguidas de outros seis, com médias variando entre 18 e 20 g. Os demais genótipos apresentaram médias inferiores a $18 \mathrm{~g}$. O índice de grãos apresentou uma média geral relativamente alta, 79,5\%. Observa-se a separação de genótipos em dois grupos, um grupo constituído por 12 genótipos que apresentou os maiores valores, embora não tenha diferido, destacaram-se a cultivar BRS-Paraguaçu e as linhagens MNC99-541F-18 e MNC99-542F-7 por apresentaram índice superior a $83 \%$.

Quanto à produtividade os genótipos produziram em média $1.436,35 \mathrm{~kg} \mathrm{ha}^{-1}$, variando de $982,0 \mathrm{~kg} \mathrm{ha}^{-1}$, na linhagem MNC99-507G-4, a 1.831,9 kg ha-1, na linhagem MNC99-542F-5. Cincos genótipos apresentaram média acima de $1.600 \mathrm{~kg} \mathrm{ha}^{-1}$. Destacaram-se as linhagens MNC99-542F-5 (1.831,9 kg ha-1), TE97-304G-12 (1.670,7 kg ha $\left.{ }^{-1}\right)$, TE96-290-12G (1.694,5 kg ha-1) e MN99-541F-18 (1.656,0 $\left.\mathrm{kg} \mathrm{ha}^{-1}\right)$ e a cultivar BRSParaguaçu (1.763,2 kg ha-1). Considera-se esses resultados relativamente semelhantes aos obtidos por Machado et al. (2008), uma vez que a média geral deste ensaio foi maior que a média de $1.399,23 \mathrm{~kg} \mathrm{ha}^{-1}$, embora $27,3 \%$ dos genótipos apresentaram média superior a $1.500 \mathrm{~kg} \mathrm{ha}^{-1}$ em cultivo irrigado.

Resultados obtidos em diversas regiões do Estado do Piauí para o cultivo feijão-caupi, mostrou-se viável economicamente sugerindo que com a adoção de um nível de tecnologia compatível com a utilização da irrigação, correção do solo, adubação, controle de ervas, controle de pragas e doenças em um hectare 
de feijão-caupi pode alcançar rendimentos médios superiores a $2.500 \mathrm{~kg} \mathrm{ha}^{-1}$, independentemente da época do ano, local de cultivo e capacidade de água disponível no solo utilizadas. No entanto, semeadura realizada em $1^{\circ}$ de fevereiro, mostrou-se a mais favorável ao cultivo irrigado do feijão-caupi no Piauí, pois proporcionou a obtenção de maiores áreas do Estado ocupadas por classes de valores de receitas líquidas mais elevadas (FREIRE FILHO et al., 2007; MOUSINHO, 2008). Já os resultados obtidos por Bastos et al. (2000) concluíram que o cultivo irrigado do feijão-caupi em Teresina-PI, com semeadura em 15 de agosto e 15 de setembro, não é recomendável economicamente.

A maioria das correlações em cultivo de sequeiro apresentou valores relativamente baixos e não significativas. Entretanto, foram semelhantes em sinal e direção (TAB. 7). Em geral, as correlações genotípicas apresentaram valores superiores às suas correspondentes correlações fenotípicas e de ambiente.

$\mathrm{O}$ caráter número de grãos por vagem mostrou correlação genotípica negativa e significativa com o peso de 100 grãos $(-0,665)$. Resultados semelhantes foram obtidos por Lopes et al. (2001), Oliveira et al. (2003) e Rocha et al. (2003). O caráter peso de 100 grãos apresentou correlação negativa e significativa com a produtividade $(-0,464)$. Lopes et al. (2001) obtiveram resultado semelhante. Entretanto, Rocha et al. (2003) e Oliveira et al. (2003) obtiveram correlações positivas e significativas para esses caracteres.

A exemplo do que foi feito no ensaio de sequeiro, os caracteres relacionados à produção de grãos em cultivo irrigado foram reunidos para o estudo das correlações, de modo que se pudessem avaliar todas as combinações entre os mesmos. De um modo geral, as correlações apresentaram coeficientes baixos e, em sua maioria, não significativas. As correlações genéticas geralmente apresentaram valores maiores que as correlações fenotípicas e de ambiente (TAB. 8).

O valor de cultivo apresentou correlações fenotípica, genotípica e de ambiente negativas e significativas com comprimento de vagem. Rocha et al. (2003) também obtiveram correlações negativas e significativas entre valor de cultivo e comprimento de vagem. O caráter número de grãos por vagem apresentou correlações fenotípica, genotípica e de ambiente negativas e significativas com o peso de 100 grãos. Este resultado está em acordo com o obtido por Rocha et al. (2003), contudo difere dos obtidos por Lopes et al. (2001) e Oliveira et al. (2003), que não detectaram significância nessas correlações. O peso de 100 grãos mostrou correlações fenotípica, genotípica e de ambiente positiva e significativa com o índice de grãos.

Tabela 7 - Estimativas dos coeficientes de correlação fenotípica (rf), genotípica (rg) e de ambiente (ra) entre caracteres de feijão-caupi, avaliados em 20 genótipos cultivados em regime de sequeiro, Teresina - PI, 2006

\begin{tabular}{|c|c|c|c|c|c|c|}
\hline Caráter $^{1}$ & $\mathrm{R}$ & COMPV & NGV & $\mathrm{P} 100 \mathrm{G}$ & IG & PROD \\
\hline \multirow{3}{*}{$\mathrm{VC}$} & $\mathrm{Rf}$ & $-0,177$ & $-0,315$ & 0,257 & 0,172 & 0,149 \\
\hline & $\mathrm{Rg}$ & $-0,212$ & $-0,450$ & 0,316 & 0,207 & 0,134 \\
\hline & $\mathrm{Ra}$ & 0,004 & 0,122 & $-0,050$ & 0,084 & 0,235 \\
\hline \multirow{3}{*}{ COMPV } & $\overline{R f}$ & & 0,423 & 0,273 & $-0,222$ & 0,040 \\
\hline & $\mathrm{Rg}$ & & 0,409 & 0,316 & $-0,333$ & 0,025 \\
\hline & $\mathrm{Ra}$ & & 0,612 & $-0,290$ & 0,283 & 0,190 \\
\hline \multirow{3}{*}{ NGV } & $\overline{\mathrm{Rf}}$ & & & $-0,632 * *$ & $-0,390$ & 0,247 \\
\hline & $\mathrm{Rg}$ & & & $-0,665^{* *}$ & $-0,700$ & 0,265 \\
\hline & $\mathrm{Ra}$ & & & $-0,540 * *$ & 0,423 & 0,176 \\
\hline \multirow{3}{*}{ P100G } & $\mathrm{Rf}$ & & & & 0,362 & $-0,440 *$ \\
\hline & $\mathrm{Rg}$ & & & & 0,390 & $-0,464 *$ \\
\hline & $\mathrm{Ra}$ & & & & 0,343 & $-0,219^{*}$ \\
\hline \multirow{3}{*}{ IG } & $\mathrm{Rf}$ & & & & & 0,097 \\
\hline & $\mathrm{Rg}$ & & & & & 0,168 \\
\hline & $\mathrm{Ra}$ & & & & & $-0,168$ \\
\hline
\end{tabular}

$\left({ }^{*}, * *\right)$ Significativo ao nível de $5 \%$ e $1 \%$, respectivamente, pelo teste $t ;{ }^{1} \mathrm{VC}$ - Valor de Cultivo; COMPV- Comprimento da Vagem; NGV - Número de Grãos por Vagem; IG - Índice de Grãos: P100G - Peso de 100 Grãos; e PROD - Produtividade 
Tabela 8 - Estimativas dos coeficientes de correlação fenotípica (rf), genotípica (rg), e de ambiente (ra) entre caracteres de feijão-caupi, avaliados em 20 genótipos cultivados sob irrigação por aspersão, Teresina, PI, 2006

\begin{tabular}{|c|c|c|c|c|c|c|}
\hline Caráter $^{1}$ & $\mathrm{R}$ & COMPV & NGV & P100G & IG & PROD \\
\hline \multirow{3}{*}{$\mathrm{VC}$} & $\mathrm{Rf}$ & $-0,507^{*}$ & $-0,069$ & $-0,083$ & 0,060 & $-0,053$ \\
\hline & $\mathrm{Rg}$ & $-0,575^{*}$ & 0,075 & $-0,085$ & 0,089 & $-0,056$ \\
\hline & $\mathrm{Ra}$ & $0,091^{*}$ & $-0,039$ & $-0,045$ & $-0,138$ & 0,001 \\
\hline \multirow{3}{*}{ COMPV } & $\mathrm{Rf}$ & & $-0,147$ & 0,340 & $-0,047$ & 0,252 \\
\hline & $\mathrm{Rg}$ & & $-0,311$ & 0,406 & 0,046 & 0,293 \\
\hline & $\mathrm{Ra}$ & & 0,585 & $-0,251$ & $-0,447$ & $-0,153$ \\
\hline \multirow{3}{*}{ NGV } & $\mathrm{Rf}$ & & & $-0,635^{* *}$ & $-0,376$ & $-0,206$ \\
\hline & $\mathrm{Rg}$ & & & $-0,644 * *$ & $-0,351$ & $-0,246$ \\
\hline & $\mathrm{Ra}$ & & & $-0,742 * *$ & $-0,465$ & 0,073 \\
\hline \multirow{3}{*}{ P100G } & $\overline{\mathrm{Rf}}$ & & & & $0,502^{*}$ & $\overline{0,101}$ \\
\hline & $\mathrm{Rg}$ & & & & $0,547^{*}$ & 0,107 \\
\hline & $\mathrm{Ra}$ & & & & $0,319^{*}$ & $-0,021$ \\
\hline \multirow{3}{*}{ IG } & $\mathrm{Rf}$ & & & & & 0,215 \\
\hline & $\mathrm{Rg}$ & & & & & 0,262 \\
\hline & $\mathrm{Ra}$ & & & & & $-0,098$ \\
\hline
\end{tabular}

$(*, * *)$ Significativo ao nível de $5 \%$ e $1 \%$, respectivamente, pelo teste $\mathrm{t} ;{ }^{1} \mathrm{VC}$ - Valor de Cultivo; COMPV- Comprimento da Vagem; NGV - Número de Grãos por Vagem; IG - Índice de Grãos: P100G - Peso de 100 Grãos; e PROD - Produtividade

Isso significa que grãos maiores tendem a apresentar a casca da vagem mais delgada.

De acordo com Andrade et al.(2010), as correlações genotípicas foram superiores às fenotípicas e ambientais, destacando-se as correlações entre valor de cultivo e produtividade de vagens frescas em 100\%. Observa-se que o coeficiente de variação genético variou de $6,58 \%$ para índice de grãos frescos a $31,62 \%$ em produtividade de grãos frescos. Destaca-se o caráter de comprimento de vagens frescas com $98,72 \%$.

O estudo e a identificação de parâmetros genéticos como: coeficiente de variação genético, herdabilidade e correlação entre caracteres são de suma importância, pois através destes podemos: conhecer a variabilidade genética, o grau de expressão de um caráter de uma geração para outra e a possibilidade de ganhos por meio da seleção direta ou indireta (ROCHA et al., 2003).

Os coeficientes de determinação genética, de variação genética e de variação ambiental em cultivo de sequeiro são apresentados na (TAB. 9). O coeficiente de determinação genética variou de médio a alto. Os maiores valores foram obtidos para comprimento de vagem $(93,29 \%)$, peso de 100 grãos $(92,29 \%)$ e produtividade (88,54\%). Mesmo os menores valores foram superiores a 50\%. Lopes et al. (2001) também obtiveram valores relativamente altos para os parâmetros comprimento de vagem e peso de 100 grãos.

Tabela 9 - Coeficiente de determinação genética e coeficientes de variação genética e ambiental dos caracteres de produtividade de grãos do feijão-caupi em regime de sequeiro, Teresina, PI, 2006

\begin{tabular}{crrrrrr}
\hline Parâmetro & \multicolumn{1}{c}{ VC } & COMPV & NGV & \multicolumn{1}{c}{ IG } & P100G & PROD \\
\hline Coeficiente de determinação genética (\%) & 75,34 & 93,29 & 77,29 & 67,27 & 92,29 & 88,54 \\
Coeficiente de variação genética (\%) & 15,64 & 5,88 & 8,06 & 3,59 & 14,99 & 15,05 \\
Coeficiente de variação ambiental (\%) & 17,89 & 3,00 & 8,73 & 5,01 & 8,66 & 10,82 \\
B & 0,87 & 1,96 & 0,92 & 0,72 & 1,73 & 1,39 \\
\hline
\end{tabular}

$(*, * *)$ Significativo ao nível de $5 \%$ e $1 \%$, respectivamente, pelo teste $t ;{ }^{1} \mathrm{VC}$ - Valor de Cultivo; COMPV- Comprimento da Vagem; NGV Número de Grãos por Vagem; IG - Índice de Grãos: P100G - Peso de 100 Grãos; PROD - Produtividade e B - razão entre os coeficientes de variação genético e ambiental 
O coeficiente de variação genética apresentou valores que variaram de $3,59 \%$ para índice de grãos a $15,64 \%$ para valor de cultivo. Para produtividade o coeficiente de variação genético foi de $15,05 \%$, abaixo de 23,90 e 19,55\%, obtidos por Lopes et al. (2001) e Rocha et al. (2003), respectivamente. O coeficiente de variação ambiental variou de 3,00\% comprimento de vagem a $17,89 \%$ no valor de cultivo, contudo os valores ficaram dentro do esperado.

Os valores do coeficiente $\mathrm{B}$ foram menores que 1,0 (um) nos caracteres valor de cultivo, número de grãos por vagem e índice de grãos, indicando que o ambiente teve maior influência na expressão desses caracteres. Entretanto, os efeitos do ambiente foram menores nos caracteres comprimento de vagem, peso de 100 grãos e produtividade.

Lopes et al. (2001), estudando a variabilidade e o potencial genético de 28 linhagens, observaram que a produtividade apresentou coeficiente de variação genético de $23,90 \%$, e o valor agronômico, de 3,56\%. $\mathrm{O}$ número de vagens por pedúnculo apresentou a menor estimativa do coeficiente de determinação genético $(4,51 \%)$, e o peso de 100 grãos, a maior $(81,74 \%)$. O coeficiente de determinação genético da produtividade foi de 34,15\%. As maiores estimativas de ganho genético foram as do peso de 100 grãos $(21,73 \%)$ e da produtividade $(19,77 \%)$.

As correlações genotípicas foram superiores às fenotípicas e às de ambiente, destacando-se as correlações entre número de ramos secundários e produtividade $(68,13 \%)$, e valor agronômico e produtividade $(100 \%)$. Estes resultados mostram amplas possibilidades de seleção entre as linhagens com relação à maioria dos caracteres estudados.
$\mathrm{Na}$ Tabela 10 verificam-se os coeficientes de determinação genética, de variação genética, de variação ambiental e da razão entre os coeficientes de variação genética e ambiental (B) em cultivo irrigado. O coeficiente de determinação genética apresentou valores relativamente altos, destacando-se a produtividade $(95,8 \%)$, o valor de cultivo $(94,6 \%)$ e peso de 100 grãos $(94,4 \%)$. O coeficiente de variação genético foi bastante amplo, variou de $3,83 \%$ no índice de grãos a $29,09 \%$ no valor de cultivo.

O coeficiente de variação ambiental variou de $3,96 \%$ no comprimento de vagem a $13,91 \%$ no caráter valor de cultivo. Os valores de $B$ variaram de 0,90 no índice de grãos a 2,40 na produtividade. Os valores das estimativas desses parâmetros nesse ensaio foram maiores que os valores do ensaio sob condições de sequeiro. Isso se deve ao melhor controle do ambiente no cultivo irrigado, com reflexo na redução dos efeitos aleatórios do ambiente nas estimativas dos parâmetros.

Matos Filho et al. (2009) avaliando genótipos promissores de feijão-caupi quanto à produtividade de grãos e arquitetura ereta de planta, obtiveram estimativas dos coeficientes de correlação fenotípica, genotípica e ambiental, para a maioria dos pares de caracteres, semelhantes em níveis de significância e magnitude, sendo consideradas baixas, quando apresentaram valores inferiores a 0,4 ; médias entre 0,4 e 0,7 ; e altas com valores superiores a 0,7 .

As correlações genotípicas, geralmente, foram superiores às ambientais e fenotípicas, demonstrando uma maior contribuição dos fatores genéticos na expressão desses caracteres.

Tabela 10 - Coeficiente de determinação genética e coeficientes de variação genética e ambiental dos caracteres de produtividade do feijão-caupi em cultivo sob irrigação por aspersão, Teresina - PI, 2006

\begin{tabular}{|c|c|c|c|c|c|c|}
\hline Parâmetro & $\mathrm{VC}$ & COMPV & NGV & IG & P100G & PROD \\
\hline Coeficiente de determinação genética (\%) & 94,60 & 84,90 & 78,20 & 76,50 & 94,40 & 95,80 \\
\hline Coeficiente de variação genética $(\%)$ & 29,09 & 4,68 & 5,12 & 3,83 & 10,98 & 15,20 \\
\hline Coeficiente de variação ambiental (\%) & 13,91 & 3,96 & 5,38 & 4,25 & 5,38 & 6,33 \\
\hline $\mathrm{B}$ & 2,09 & 1,18 & 0,95 & 0,90 & 2,04 & 2,40 \\
\hline
\end{tabular}

$\left(*\right.$,**) Significativo ao nível de $5 \%$ e $1 \%$, respectivamente, pelo teste $t ;{ }^{1}$ VC- Valor de Cultivo; COMPV- Comprimento da Vagem; NGV Número de Grãos por Vagem; IG - Índice de Grãos: P100G - Peso de 100 Grãos; PROD - Produtividade e B - razão entre os coeficientes de variação genético e ambiental 


\section{Conclusões}

1. A maioria das correlações em cultivo de sequeiro e irrigado apresentou valores relativamente baixos e não significativas. Entretanto, foram semelhantes em sinal e direção;

2. Em geral, as correlações genotípicas apresentaram valores superiores às suas correspondentes correlações fenotípicas e de ambiente, tanto em cultivo de sequeiro quanto irrigado;

3. As linhagens TE96-290-12G, TE97-304G-12, MNC99-510F-16, MNC99-541F-15 e MNC99$547 \mathrm{~F}-2$ apresentaram crescimento, desenvolvimento e produtividades semelhantes à das cultivares BR17Gurgéia e BRS-Marataoã no cultivo de sequeiro;

4. As linhagens TE96-290-12G, TE97-304G-4, TE97304G-12, TE97-309G-18, TE97-309G-24, MNC99510F-16, MNC99-541F-18 e MNC99-542F-5 e a cultivar BRS Paraguaçu foram as mais produtivas no sistema de cultivo irrigado.

\section{Referências}

ANDRADE JÚNIOR. A. S. de et al. Níveis de irrigação na cultura do feijão-caupi. Revista Brasileira de Engenharia Agrícola e Ambiental, v. 06, n. 01, p. 17-20, 2002.

ANDRADE, F. N. et al. Estimativas de parâmetros genéticos em genótipos de feijão-caupi avaliados para feijão fresco. Revista Ciência Agronômica, v. 41, n. 2, p. 253-258, 2010.

BASTOS, E. A. et al. Manejo econômico da irrigação de feijãocaupi via modelo de simulação. Irriga, v. 5, n. 2, p. 84-98, 2000.

CARDOSO, J. M.; MELO, F. de B.; LIMA, M. G. Ecofisiologia e manejo de plantio. In: FREIRE FILHO, F.R.; LIMA, J.A. de A.; RIBEIRO, V.Q. Feijão caupi: avanços tecnológicos. Brasília: EMBRAPA, 2005. p. 211-228.

CARDOSO, M. J. et al. Dose de fósforo e densidades de planta em caupi. II. Efeito sobre a produtividade de grãos e componentes de produção sob irrigação em solo Aluvial Eutrófico. In. REUNIÃO NACIONAL DE PESQUISA DE CAUPI, 4, 1996, Teresina. Resumos... Teresina: Embrapa-CPAMN, 1996. p. 123.

CARDOSO, M. J.; RIBEIRO, V. Q. Desempenho agronômico do feijão-caupi, cv. Rouxinol, em função de espaçamento entre linhas e densidade de plantas sob regime de sequeiro. Revista Ciência Agronômica, v. 37, n. 01, p. 102-105, 2006.

CARVAlHO, F. I. C.; LORENZETTI, C.; BENIN, G. Estimativas e implicações da correlação no melhoramento vegetal. Pelotas: Universidade Federal de Pelotas, 2004. 142 p.

CRUZ, C. D.; REGAZZI, A. J. Modelos biométricos aplicados ao melhoramento genético. Viçosa: UFV- Imprensa Universitária, 1994. 390 p.
EMBRAPA, Centro Nacional de Pesquisa de Solos (Rio de Janeiro, RJ). Sistema Brasileiro de Classificação de Solos. Brasília: Embrapa Produção da Informação; Rio de Janeiro: Embrapa Solos, 1999. 412 p.

FREIRE FILHO, F. R. et al. Adaptabilidade e estabilidade da produtividade de grãos de genótipos de caupi enramador de tegumento mulato. Pesquisa Agropecuária Brasileira, v. 38, n. 05, p. 591-598, 2003.

FREIRE FILHO, F. R. et al. Adaptabilidade e estabilidade da produtividade de grãos de linhagens de caupi de porte enramador. Revista Ceres, v. 49, n. 234, p. 383-393, 2002.

FREIRE FILHO, F. R. et al. Adaptabilidade e estabilidade de rendimento de grãos de genótipos de caupi de porte semi-ereto. Revista Científica Rural, v. 06, n. 02, p. 31-39, 2001.

FREIRE FILHO, F. R. et al. Caracterização de pólos de produção da cultura de feijão-caupi no estado o Piauí. Embrapa Meio Norte, 2007, 28p. (Documento, 100).

FREIRE FILHO, F. R. et al. Cultivares de caupi para a região Meio-Norte do Brasil. In: CARDOSO, M. J. (Org.). A cultura do feijão caupi no Meio-Norte do Brasil. Teresina: Embrapa Meio-Norte, 2000. 264p. (Embrapa Meio-Norte. Circular Técnica, 28).

IBGE. Levantamento Sistemático da Produção Agrícola (LSPA) - 1997-2006.

KEMPTHORNE, O. An introduction to genetic statistics. Ames: The State University Press, 1973, 454 p.

LOPES, A. C. de A. et al. Variabilidade e correlações entre caracteres agronômicos em caupi (Vigna unguiculata). Pesquisa Agropecuária Brasileira, v. 36, n. 03, p. 515-520, 2001.

MACHADO, C. F. et al. Identificação de genótipos de feijão-caupi quanto à precocidade, arquitetura da planta e produtividade de grãos. Revista Ciência Agronômica, v. 39, n. 01, p. 114-123, 2008.

MATOS FILHO, C. H. A. et al. Potencial produtivo de progênies de feijão-caupi com arquitetura ereta de planta. Ciência Rural, v. 39, n. 02 , p. $348-354,2009$.

MOUSINHO, F. E. P.; ANDRADE JÚNIOR, A. S. de; FRIZZONE, J. A. Viabilidade econômica do cultivo irrigado do feijão-caupi no Estado do Piauí. Acta Scientiarum. Agronomy, v. 30, n. 1, p. 139-145, 2008.

OLIVEIRA, A.P. et al. Avaliação de linhagens e cultivares de feijão-caupi, em Areia, PB. Horticultura Brasileira, v. 20, n. 02, p. 180-182, 2002.

OLIVEIRA, F. J. de et al. Caracteres agronômicos aplicados na seleção de caupi. Revista Ciência Agronômica, v. 34, n. 01, p. 44-50, 2003.

ROCHA, M. de M. et al. Controle genético do comprimento do pedúnculo em feijão-caupi. Pesquisa Agropecuária Brasileira, v. 44, n. 03 , p. $270-275,2009$.

ROCHA, M. de M. et al. Estimativas de parâmetros genéticos em genótipos de caupi de tegumento branco. Revista Científica Rural, v. 08, n. 01, p. 135-141, 2003. 
ROCHA, M. M. et al. Avaliação agronômica de genótipos de feijão-caupi para produção de grãos verdes. Teresina: Embrapa Meio-Norte. 2006. 16 p. (Boletim de Pesquisa e Desenvolvimento, 67).

SANTOS, C. A. F.; ARAÚJO, F. P. Produtividade e morfologia de genótipos de caupi em diferentes densidades populacionais nos sistemas irrigados e de sequeiro. Pesquisa Agropecuária Brasileira, v. 35, n. 10, p. 1977-1984, 2000.

SANTOS, C. A. F.; ARAÚJO, F. P.; MENEZES, E. A. Comportamento produtivo de caupi em regimes irrigado e de sequeiro em Petrolina e Juazeiro. Pesquisa Agropecuária Brasileira, v. 35, n. 11, p. 2229-2234, 2000.
SCOTT, A. J.; KNOTT, M. A. A cluster analysis method for grounping means in the analysis of variance. Biometrics, v. 30, n. 03, p. 507-512, 1974.

TÁVORA, F. J. A. F. et al. Arranjo e população de plantas em cultivares de feijão-de-corda com diferentes características de copa. Revista Ciência Agronômica, Fortaleza, v. 32, n. 1/2, p. 69-77, 2001.

TEÓFILO, E. M. et al. Potencial fisiológico de sementes de feijão caupi produzidas em duas regiões do Estado do Ceará. Revista Ciência Agronômica, v. 39, n. 03, p. 443-448, 2008. 